\title{
Injury Prevention, Safe Training Techniques, Rehabilitation, and Return to Sport in Trail Runners
}

\author{
Heather K. Vincent, Ph.D., Michael Brownstein, M.D., and Kevin R. Vincent, M.D., Ph.D.
}

\begin{abstract}
This current concept, narrative review provides the latest integrated evidence of the musculoskeletal injuries involved with trail running and therapeutic strategies to prevent injury and promote safe participation. Running activities that comprise any form of off-road running (trail running, orienteering, short-long distance, different terrain, and climate) are relevant to this review. Literature searches were conducted to l) identify types and mechanisms of acute and chronic/ overuse musculoskeletal injuries in trail runners, 2) injury prevention techniques most relevant to running trails, 3) safe methods of participation and rehabilitation timelines in the sport. The majority of acute and chronic trail running-related musculoskeletal injuries in trail running occur in the lower leg, primarily in the knee and ankle. More than $70 \%$ are due to overuse, and ankle sprains are the most common acute injury. Key mechanisms underlying injury and injury progression include inadequate neuromotor control-balance-coordination, running through fatigue, and abnormal kinematics on variable terrain. Complete kinetic chain prehabilitation programs consisting of dynamic flexibility, neuromotor strength and balance, and plyometrics exercise can foster stable, controlled movement on trails. Patient education about early musculoskeletal pain symptoms and training adjustment can help prevent injury from progressing to serious overuse injuries. Real-time adjustments to cadence, step length, and knee flexion on the trail may also mitigate impactrelated risk for injury. After injury occurs, rehabilitation will involve similar exercise components, but it will also incorporate rest and active rest based on the type of injury. Multicomponent prehabilitation can help prevent musculoskeletal injuries in trail runners through movement control and fatigue resistance.
\end{abstract}

\section{Introduction}

$\mathbf{T}$ rail running encompasses a broad spectrum of running experiences, but it occurs off-road in the natural environment on surfaces with a maximum of $20 \%$ paving. Trail running comprises a unique combination of variations in elevation, discontinuous running surfaces, global location, and a climate that ranges from desert to mountain to forest. Distances range from a few

From the Department of Physical Medicine and Rehabilitation, University of Florida College of Medicine, Gainesville, Florida, U.S.A.

The authors report the following potential conflicts of interest or sources of funding: H.K.V. and K.R.V. are both Associate Editors for Medicine and Science in Sports and Exercise. H.K.V.'s research is supported, in part, by Lallemand, Inc. Full ICMJE author disclosure forms are available for this article online, as supplementary material.

Received September 1, 2021; accepted September 22, 2021.

Address correspondence to Heather K. Vincent, Ph.D., F.A.C.S.M., Department of Physical Medicine $\theta$ Rehabilitation, University of Florida Health Sports Performance Center, 3450 Hull Road, PO Box 112730, University of Florida, Gainesville, FL 32611, U.S.A. E-mail: hkvincent@ufl.edu

(C) 2021 THE AUTHORS. Published by Elsevier Inc. on behalf of the Arthroscopy Association of North America. This is an open access article under the CC BY-NC-ND license (http://creativecommons.org/licenses/by-nc-nd/4.0/).

2666-061X/211277

https://doi.org/10.1016/j.asmr.2021.09.032 kilometers to $80+$ kilometers, with event differences in schedule ranging from single to multiday. The International Trail Running Association (ITRA) assigns ITRA points (0-6) to classify difficulty based on distance and elevation gain. ${ }^{1}$ Trail orienteering involves running on trails or off trails, and distances range from short $(4-5 \mathrm{~K}$ versions) up to long courses $(\geq 10 \mathrm{~K})$. Orienteering is a map-reading, skill-related sport that involves navigation through trail or off-trail areas, covering distance while being timed. ${ }^{2}$ Traditional orienteering combines running with navigation through natural areas to acquire as many points as possible. Depending on the location and event, the competition can be single or multiday. Runners are challenged by the presence of fallen trees, branches, roots, rocks, and unanticipated variability underfoot. The risks for specific injuries and injury prevention and safe participation are unique compared to regular outdoor running. In this current concepts article, the injuries reported with participation in trail running activities are highlighted, with prehabilitation and rehabilitation techniques and considerations for safe participation.

Literature searches were conducted in several databases (PubMed, CINAHL, MEDLINE Ovid, Scopus) from 1975 to the present to provide relevant evidence 
synopses of 1) prevalence, type, and mechanisms of acute and chronic/overuse musculoskeletal injuries in trail runners; 2) injury prevention techniques most relevant to running trails; and 3) safe methods of participation in the sport.

\section{Musculoskeletal Injury Epidemiology}

Most evidence of injury patterns with trail running are from surveys, primarily from single-day events. ${ }^{3-8}$ Irrespective of global location, the lower leg (knee through the foot) is the most common region for acute and chronic injuries. ${ }^{4-7,9}$ One study from Greece found that the low back and the knee were the most frequently injured locations, but the most severely injured location was the Achilles tendon. ${ }^{8}$ Specific musculoskeletal injuries are patellofemoral pain syndrome, muscle strains (quadriceps femoris, hamstrings, tibialis anterior, calf, back), Achilles tendinopathy, trochanteric bursitis, iliotibial band (ITB) syndrome, ankle inversion injuries, plantar fasciitis, and stress fractures (foot, tibia).

\section{Acute Trail Running Injuries}

After the largest $161-\mathrm{km}$ races in North America (Western States Endurance Run, Vermont Endurance Race) entrants were provided postrace questionnaires. ${ }^{10}$ A total of $36.5 \%$ of finishers reported muscle pain, with most of the acute injuries occurring in the knee, lower leg, hamstring, plantar fascia, and calf. ${ }^{10}$ Across multiday events, such as the Al Andalus Ultra Trail (219-km, 5day race) in the mountainous areas of Spain, knee pain was the most common complaint-after blisters and chafing-followed by ankle pain $(83 \%$ were ankle inversion sprains). ${ }^{11}$ Among an international cohort of orienteers, acute injuries were captured during the Jukola and Venla relay competitions, which range in duration from one to five days. ${ }^{12}$ While $70 \%$ of the injuries treated on-site were in the lower extremities, the most common injury was ankle sprain $(25 \%$ of all acute injuries), with most of these ankle injuries occurring in the first third of the race. ${ }^{12}$

\section{Chronic/ Overuse Injuries}

The knee and ankle are the most common sites for overuse injury. ${ }^{6}$ Cross-sectional data collected over four trail races revealed that of the total respondent pool, $22 \%$ had suffered ITB syndrome, $10 \%$ had Achilles tendon injury, $9 \%$ had hamstring injuries, and $7 \%$ had calf muscle injury over the last 12 months, with an additional $19 \%$ reporting chronic injuries to the knee and lower leg. ${ }^{3}$ Among the 2019 SkyRace competitor pool, muscle/tendon accounted for $44.1 \%$ of tissue type injuries. Tendinopathy $(27.5 \%)$, joint sprain $(19.6 \%)$, and muscle injury $(15.7 \%)$ were the most common pathologies reported.

Adolescent athletes who performed a 26-week season of orienteering, were surveyed on the web for injury patterns. ${ }^{13}$ Overall, there were 18 injuries per 1,000 hours of training. Acute and chronic injuries were $48.6 \%$ in foot/lower leg, $22.9 \%$ for knee, $11.9 \%$ for hip, and $6.4 \%$ for lower back. Higher distribution was shown for foot/lower leg in girls than boys $(75.8 \%$ vs $45.2 \%)$, knee injuries more common in boys. Among orienteers, most injuries occur in the lower extremities with $72 \%-78 \%$ as overuse injuries. ${ }^{13,14}$ Specific diagnoses include medial shin pain, Achilles peritendinitis, peroneal tenosynovitis, and ITB friction syndrome. ${ }^{15}$ Prehabilitation and rehabilitation therapies should target lower body strengthening, and movement control across the kinetic chain.

\section{Potential Mechanisms of Injury and Injury Progression}

Running on trails requires rapid cognitive processing of the environment, responsiveness to variations in ground surface, avoidance of obstacles, and adjustment to elevations in terrain. To maintain stability, runners use anticipatory, predictive, and reactive balance control strategies. ${ }^{16}$ Neuromotor responses are activated to react to the disturbance or obstacle in the path without prior planning. ${ }^{17,18}$ Trail surface materials (gravel, dirt, or paving) are not associated with differential tibial impact forces, ${ }^{19}$ and are not likely a primary injury mechanism. However, inadequate dynamic muscle strength, deficits in neuromotor control about the lower extremity joints and abnormal motion of loaded joints are potential mechaisms. ${ }^{20,21}$ Fig 1 provides an overview of mechanical challenges relating to trail running and counteractive strategies needed to promote safe motion.

\section{Loading and Loading Impact}

Compared to level running, downhill running produces greater vertical and transverse peak accelerations at the tibia, especially along the anteromedial aspect. ${ }^{22,23}$ Peak accelerations are increased at the sacrum and the head. ${ }^{22,24}$ To cushion impacts, runners need more knee flexion, hip flexion, and plantarflexion, ${ }^{22}$ which can facilitate more vertical alignment of the tibia, while reducing ankle stiffness and increasing knee stiffness. During trail runs, preparedness for repetitive braking is important. Bone (especially cortical bone) is weaker against shear than compressive strains, ${ }^{25}$ and poorly controlled impact loading may contribute to bone failure and stress fracture.

\section{Running Through Fatigue}

Fatigue creates a myriad of biomechanical problems. Redistribution of muscular activity or change in the profile of muscle activity occurs with fatigue. ${ }^{24,26}$ Stance time during the gait cycle is lengthened, thereby placing elevated volume of mechanical stress on the musculoskeletal system. ${ }^{27}$ Fatigue increases 


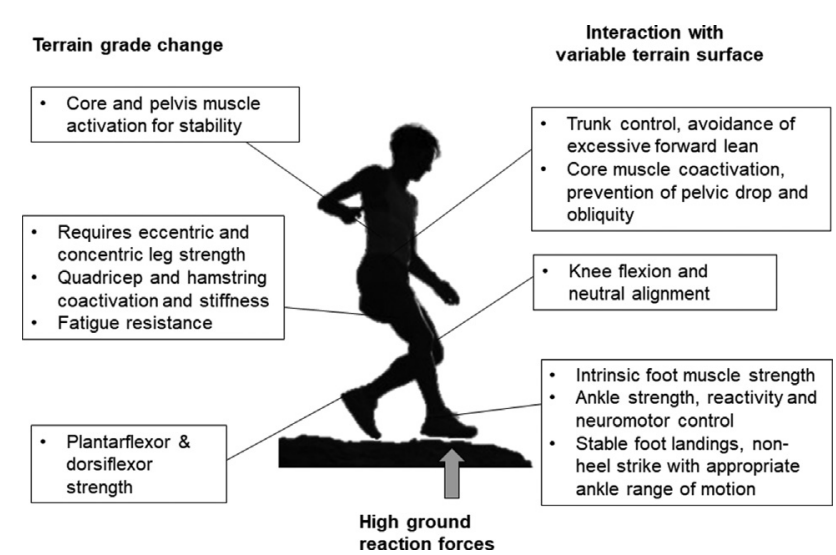

Fig 1. Key mechanical stresses to the musculoskeletal system during trail running and motion strategies required to mitigate injury risk.

loading at the lateral and medial areas of the heel, first metatarsal and hallux, and in lesser toes during pushoff in rearfoot strikers; among forefoot strikers, fatigue increases the loading on the first to third metatarsals and the medial-lateral force ratio during stance and push-off. ${ }^{27}$ Impact peaks and loading rates increase by 6-11\% during exhaustive running, with greatest force changes occurring at the knee and calf/foot/ankle. ${ }^{28}$ Inability to control running motion increases the risk for motion errors, asymmetries, and the capacity to appropriately dissipate force. Better stability after landing and a higher hamstring/quadricep ratio will help control impact forces. ${ }^{29}$ For trail runners who already have nagging musculoskeletal complaints, running through fatigue can exacerbate the mechanics that triggered the pain to begin with. Exercise that promotes fatigue resistance may help mitigate pain and injury progression.

\section{Abnormal Joint Motion}

Joint motion and excursion from the trunk to the foot in the three planes of movement can become exaggerated with running speed, ${ }^{30}$ fatigue, ${ }^{31}$ and inadequate muscle strength. ${ }^{32,33}$ Forward trunk lean by $\sim 3^{\circ}$ is associated with running injuries. ${ }^{34}$ Elevated contralateral pelvic drop $\left(2.1^{\circ}\right)$ and anterior pelvic tilt $\left(3.1^{\circ}\right)$ and longer stance times are related to recurrent calf strain injuries. ${ }^{35}$ Peak contralateral pelvic drop has also been associated with patellofemoral pain, ITB syndrome, medial tibial stress syndrome and Achilles tendinopathy. ${ }^{34}$ Mechanistically, pelvic drop increases ITB tension and compression at the femoral condyle and increases lateral displacement of the patella. Pelvic drop will also shift the ground reaction force vector medially and produce a bending force on the medial tibia. ${ }^{34}$ Sidestep cutting, which is encountered on trails, requires generation of adequate lumbosacral lateral flexion torque and hip flexor activation to neutralize pelvic drop on the free side of the pelvis, prevent pelvic obliquity, and protect against injury to the lumbopelvic regions and lateral flexors. ${ }^{30,36}$ Gluteus medius stabilization and hip abductor-core muscle strengthening will help develop proximal control to counteract these issues. ${ }^{32}$ Distal movement control is also involved in injury onset. Excessive pronation and lateral roll-off during the push off phase is related to lower leg pain with running. ${ }^{37}$ Injured runners have $1.4^{\circ}$ more peak rearfoot eversion than noninjured runners. ${ }^{34}$ Prehabilitation should include exercises that target ankle and foot stability in all planes of movement, preferably coupled with unstable surface and balance elements. When landings on the ground occur with the knee angles close to full extension, as in steep decline slope terrain or hilly uneven surface, neuromuscular control of dynamic lower extremity valgus is critical. ${ }^{38}$ This control involves maintenance of normal hip adduction, knee abduction, and ankle eversion through mitigation of knee valgus forces, and knee external rotation. ${ }^{39,40}$

Muscle stiffness is the ability of a muscle to resist deformation with an applied force. The musculoskeletal tissue complex of the lower extremities must generate some stiffness properties to store elastic energy during the stance phase of gait and generate concentric force at push-off. Higher knee joint stiffness is the result of eccentric contraction of quadriceps, less knee flexion, or both, and inhibits energy dissipation, which can injure structures of the knee. ${ }^{41}$ High levels of stiffness lead to heightened injury risk to the proximal anterior tibia, ${ }^{42}$ whereas low stiffness contributes to soft-tissue injury (such as ACL, Achilles tendon) through excessive joint motion at the knee, ankle, and hip. ${ }^{42,43}$ Bilateral differences in leg stiffness are related to leg injuries to the hamstring, calf, groin, ankle, and quadriceps with running. ${ }^{44}$ Injury may occur with discordant stiffness control from the limb to individual joints; some evidence suggests that elevated overall leg stiffness and low ankle stiffness contributes to injury at the Achilles tendon. ${ }^{43}$ Messier et al. ${ }^{41}$ reported that excessive knee stiffness predicted injury over 2 years. This may be corrected in real time by shortening step lengths. ${ }^{41}$ Managing joint and leg stiffness may be more concerning among people with higher body weights; ${ }^{41,45}$ additional adaptation time and slower progression rates with training may be required. Prehabilitation to develop appropriate stiffness and movement control include plyometrics, jump landings, and eccentric muscle training.

\section{Running Through Noncritical, Chronic Pain}

Runners with persistent musculoskeletal pain demonstrate altered mechanics. For example, patellofemoral pain is related to elevated frontal plane knee excursion and less knee flexion and less pelvic drop on the unloaded side. ${ }^{46}$ Runners with ITB pain increase hip adduction at foot contact, knee rotation during the 
A Flexibility

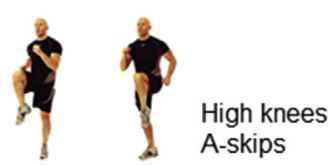

Hip circles
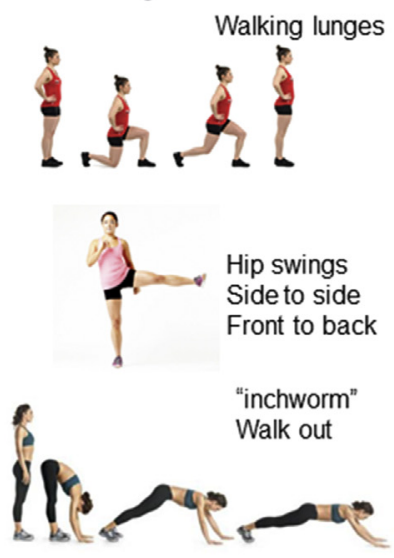

B

Neuromuscular Strengthening

\& Balance

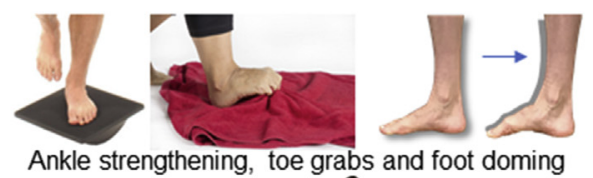

Ankle strengthening, toe grabs and foot doming

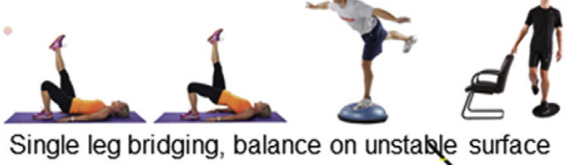

Single leg bridging, balance on unstakle surface
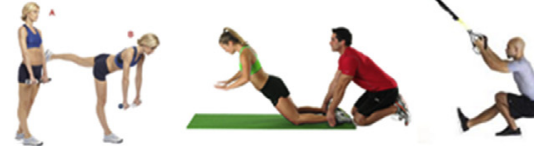

Romanian deadlift, Nordic curls, single leg squats
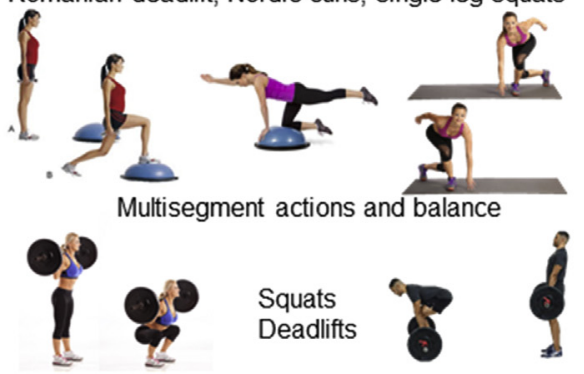

C Plyometrics
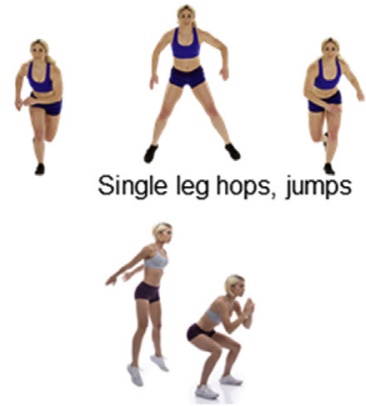

Squat or countermovement jumps
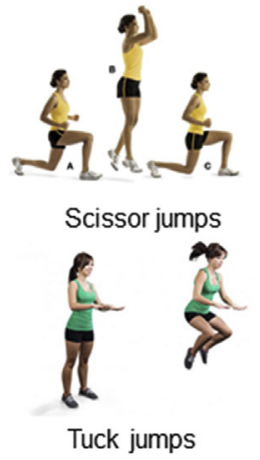

Fig 2. Sample exercises for trail runners as part of prehabilitation and rehabilitation programs. (A) Dynamic multijoint flexibility movements. (B) Neuromuscular strengthening and balance. (C) Plyometric activities.

stance phase and knee abduction at push-off compared to runners without this pain. ${ }^{46}$ Running through pain can produce compensatory biomechanics and loading at other anatomical sites. Our clinical experience is that runners with initial pain at one site who continue training develop secondary pain(s) elsewhere.

\section{Injury Prevention and Rehabilitation}

Prevention of trail running injuries requires a multifaceted approach, including education, strengthening, and flexibility exercise, neuromotor control exercise, and plyometrics. Sample exercises are presented in Fig 2.

\section{Education About Musculoskeletal Pain}

Four key rules can be used to educate runners before an injury becomes serious. ${ }^{47}$ Pain affects up to $79 \%$ of runners, but many do not know how to interpret pain to determine continuation of training. These rules are 1) running should be stopped immediately if pain increases during a run, or changes in quality from achy to sharp; 2) joint pain should not linger or increase by 24 hours after a run, as this indicates that the volume was excessive and should be scaled back, 3) if preexisting pain is present $(<3$ points out of a 10 -point numerical pain rating scale), this pain should not increase during the run or persist into the next day, and 4) run-training should stop until pain-induced compensation to running form disappear (foot interaction with the ground, limping, hiking a hip). ${ }^{47}$ These rules can guide trail running participation to avoid serious injury in the first place.

\section{Evaluation of Running Mechanics}

Prior to serious preparation for trail events, a medically based running analysis should be performed to identify deficits in motion. ${ }^{48}$ Debriefing with the runner and gait-retraining sessions could be conducted that use real-time visual feedback. Abnormal kinematics and pain associated with common running injuries can be effectively addressed with $8-18$ sessions over 2-6 weeks. ${ }^{49,50}$ Running motion analysis is also a critical part of the return-to-run program during rehabilitation postinjury.

\section{Incorporating Flexibility}

Conflicting evidence exists on frequency and type of stretching to prevent overuse injury. ${ }^{41}$ Static measures of flexibility may not meaningfully translate to the dynamic processes in the running motion. ${ }^{51-54}$ Other studies report that greater hamstring flexibility can lower the risk for incurring a lower leg overuse injury. ${ }^{55}$ Prospective evidence shows that there is no difference in plantar flexor, ankle dorsiflexor, hamstring, and quadricep flexibility among runners 
who do and do not develop overuse injuries over two years. $^{41}$ We propose a dynamic warm-up before training or competition that includes some movements from successful injury prevention programs (FIFA $11+) .{ }^{56}$ These movements involve multisegment coordination and the lower body, such as A-skips, walking lunges, vertical jumps, standing hip in-out circles, quick running forward and backwards, hip swings, and inchworm walk-out. (Fig 2, left panel)

\section{Strengthening the Kinetic Chain}

Kinetic chain strengthening from the foot through the trunk, neuromotor control, and plyometric exercise are key components. An important point to note is that inadequate lower extremity strength (hip abductors, knee flexors/extensors, ankle plantar/dorsiflexors) is commonly cited risk for increasing impact force transmission and running-related injuries. ${ }^{29,57}$ Yet, there is inconsistent evidence supporting that low strength metrics alone are associated with injury, ${ }^{41,57}$ hip angles, ${ }^{58}$ muscle activation, and neuromotor control. ${ }^{59,60}$ Low hip abduction strength may be related to ITB syndrome, but not strongly to patellofemoral pain, tibial stress syndrome, or fracture or Achilles tendinopathy. ${ }^{32}$ Moreover, hip/knee strengthening intervention studies often use maximal strength measures to predict injury risk, ${ }^{61}$ rather than how that strength is used during running motion.

An overall strong movement and controlled motion through appropriate activation of the muscles along the kinetic chain during the gait cycle is more likely to prevent injury rather than strength capacity. Reducing possible deficits in stability after landing from the foot to the trunk (distal-to-proximal), developing hamstring and quadriceps strength in the elongated muscle range, and maintaining a balanced ratio of hamstring/quadriceps strength could help to reduce the injury risk. ${ }^{29,62}$ Inclusion of therapeutic exercises that increase strength while enhancing proprioception and responsiveness to the environment is also vital for strong running motion. From the implementation perspective, instruction of the movements may be more effective with external focus, which enables the athlete to perform the exercise without losing natural, automatic coordination. ${ }^{63}$ Instruction should foster positive changes in motion in response to the environment around the runner.

\section{Foot Strengthening}

Through the unique, complex arch structures and strong intrinsic and extrinsic muscle activity, the foot provides postural corrections, stability, maintenance, and control of foot arches and torque production for body movement. ${ }^{64,65}$ Moreover, the foot muscles store strain energy and return elastic energy, change arch stiffness, and provide sensorial feedback. ${ }^{65,66}$ With each footstep, the foot must be stable at foot strike and pushoff, and during stance, it must be adaptable to attenuate loads and control motion. ${ }^{65}$ For trail runners, the neuromotor response must adapt quickly to variations on the ground surface and changes in slope while dampening loading forces.

A variety of exercises that foster muscle endurance, control of ankle motion, and activation of the intrinsic foot muscles can improve force transmission through the foot, increase arch stiffness improve vertical propulsive forces, and effectively increase foot muscle volume. ${ }^{66}$ Volume of the abductor hallucis, flexor digitorum brevis, and flexor hallicus brevis can occur in as little as 8 weeks. ${ }^{66}$ Specifically, barefoot standing and seated and gait exercises should be incorporated on a regular basis for prevention of injury. Standing exercises include tapping with a fixed heel, calf presses, and plantar arch raises. From a seated position, performing alternation of inversion/eversion, grabbing a cotton ball, rubber ball, or a pen with heel fixed on the ground, alternating in one foot pressing the hallux and little toe on the floor slowly and with control, toe spreading though toe abduction and "short foot" or "doming" exercise. Short foot exercise, or 5-second isometric contraction holds that raises the arch, $(2-3 \times$ week for 4-8 weeks) can increase foot muscle volume and functionally improve foot stability. ${ }^{67}$ There is crossover benefit of short foot exercise on knee pain and hip strength $^{68}$ and knee flexion torque, demonstrating improved transfer through the body segments to faster running speed. ${ }^{69}$ Finally, barefoot gait exercises that use the toes differently than during normal walking are useful. A toe-grasping gait involves performing sets of 10 steps in which the toes of each foot grasp the ground and hold for three seconds. A toe-abducted gait involves performing sets of 10 steps forward and backward with toes abducted until the foot lifts from the ground. ${ }^{66}$ These foot exercises train the foot to activate the small intrinsic muscles that help control the initial impact loading and stability during stance and push-off. (Fig 2, middle panel)

\section{Trunk and Lower Body Neuromuscular Strength and Balance}

The trunk is an anchor for proximal control of running motion, and inadequate motor control is related to dynamic instability and injuries. ${ }^{70}$ Developing optimal muscle activation patterns about the abdomen, back paraspinals, and pelvis as a "core unit" can help control the interaction of the body and ground. Athletes who produce greater muscle activation at the gluteal muscles, lumbar extensors and rectus abdominis incur fewer hamstring injuries over time than athletes with less muscle activation during running. ${ }^{71}$ This abdominal bracing counteracts buckling and shear instability. ${ }^{70}$ Effective movements that facilitate trunk strengthening 
can be supine and standing, and they should include bridging (dual or single leg, on physioball, on wobbly surface), quadruped with alternating leg/arm raises, variations of the front and side plank, physioball exercises (seated or marching, spinal flexion and extension with a 5-10-pound medicine ball, abdominal rollout and pike tucks). Standing exercise should incorporate singleleg balance on a rocker board in all three planes, and practicing "falling forward" into an unstable rocker board. ${ }^{70}$

Given the variability of the terrain and unanticipated challenges on a course, neuromuscular control of the lower extremity is critical for safe trail running. Control can be developed through exercises that involve simultaneous application of strength, flexibility, and balance-coordination. Improvement in postural stability at the trunk and reduction in movement error ${ }^{72}$ is achieved through learned muscle coactivation that stabilizes joints along the kinetic chain during dynamic motion. This type of exercise should be done routinely, 3-4 times a week. Benefits on biomechanical injury risk reduction have been observed in studies ranging from 6-14 weeks of duration. ${ }^{39,72}$ Neuromuscular strength exercise with balance can include forward and lateral line jumps with deep holds on landing, single leggedsquats with deep hold, balancing on a BOSU Ball (single leg, squats, or box drops with a deep hold), single-leg pelvic bridges (transition to performing on BOSU or physioball), walking lunges that transition to lunges with Swiss ball and trunk rotations, standing hip abductions with resistance, single-legged skater squats, Romanian deadlifts, and standing toe taps while on a single leg. ${ }^{39}$ For some runners, initially performing these exercises is difficult without assistance until strength and coordination are developed. Runners with low strength who are prescribed single-leg squats may begin using a cable suspension system and perform partial squats to ensure the form is correct; as strength improves over time, the runner can progressively increase the depth of the squat or eliminate the suspension support and perform the full exercise appropriately. Wobble board-based exercises (multiple times per week, up to 20 minutes) perturb balance and require coordinated muscle activation to maintain balance and position, and can decrease the relative risk for acute lower extremity and ankle injury to $.71 .{ }^{73}$ During single-leg landing tasks, wobble board training (board rocking in different planes, combined arm and leg movement, single-leg squats, ball bouncing or throwing, air taps on balloon, eyes closed balance) can increase the eccentric ankle work by 1.2-4.4 times in the frontal and transverse planes, and modify the muscle recruitment to optimize early ankle stabilization after landing. $^{74}$

Quadricep and lower-leg musculature must be strong for uphill and downhill navigation. Barbell exercise with concentric and eccentric actions to the lower limb muscles includes squats (back, front, split), deadlifts, and lunges. These exercises are vital for muscle power, plantarflexion, and knee extension strength ${ }^{75}$ and controlled descent with changes in terrain. Hamstring injury incidence can be mitigated through exercise performed twice per week, with no additive protective benefit with more weekly sessions or progression in volume or intensity. ${ }^{76}$ Thus, for hamstrings, weekly consistency of exercise to combat injury is critical. Incorporation of eccentric strengthening and stability/ balance-based exercise into prevention programs affords significant protection on hamstring health. ${ }^{76} \mathrm{In}$ clusion of the Nordic hamstring exercise alone as part of prevention training cuts the incidence of hamstring injuries by $51 \%$ in running athletes. ${ }^{77}$ These exercises may improve intermuscular coordination and joint stability and reduce knee valgus during load-bearing. ${ }^{78}$

Exercises involving core and trunk musculature, such as quadruped alternate arm raises (Superman), side bridges, crossover crunches, hip thrust, unilateral calf raises with dumbbells, and seated marching on a physioball are critical. $^{79,80}$ These exercise programs were associated with performance gains on balance tests $^{80}$ and a reduction in relative risk for lower extremity injury from 2.53 to .38 , with greatest protection against medial tibial stress syndrome; some protection was afforded against ankle sprain, knee tendinopathy, and knee bursitis. ${ }^{79}$ After learning these exercises under supervision from a physical therapist, the runner can perform these exercises at home with periodic filming from sagittal and frontal views to ensure that the form is retained outside of the therapeutic environment. Adjustments can be made in real time to correct any lingering movement deficits (Fig 2, middle panel).

\section{Plyometrics}

Plyometric training comprises movements with serial stretch-shortening cycles that cause repeated lengthening and shortening of muscle-tendon complexes. These exercises commonly include variations of drop jumps, tuck and scissor jumps, squat jumps, countermovement jumps, and hopping (single- or dual-legged; Fig 2, right panel). ${ }^{81}$ This exercise type enhances neuromuscular reactivity through facilitation of the sensorimotor system. Adaptations include improved neural drive to agonists, improved intermuscular coordination and activation strategies, and favorable changes to mechanical qualities and architecture of the muscle-tendon complex. Plyometrics can help reduce serious knee injuries. ${ }^{82}$ When coupled with prevention training programs, plyometrics can reduce ground reaction forces by $17-26 \%$ over $6-9$ weeks. ${ }^{81}$ An interventional program in elite orienteers included the incorporation of one-leg stance, runner's pose, one leg 
Table 1. Overview of Rehabilitation Program Design for Trail Running-Related Injuries, Numbers Listed Are in Weeks from the Time Point of Diagnosis

\begin{tabular}{|c|c|c|c|c|c|c|}
\hline & Rest from Running* & $\begin{array}{l}\text { Core Stabilization Leg } \\
\text { Strength }\end{array}$ & Nonimpact Conditioning & $\begin{array}{l}\text { Jump Training and } \\
\text { Plyometrics }\end{array}$ & $\begin{array}{c}\text { Walk-Jog Intervals Return-to- } \\
\text { Run }\end{array}$ & Hills \\
\hline \multicolumn{7}{|l|}{ Overuse } \\
\hline Soft tissue injuries & $\begin{array}{l}0 \text { days- until running } \\
\text { with normal } \\
\text { motion }\end{array}$ & $\begin{array}{l}\text { Immediately, } 0 \text { days for } \\
\text { both }\end{array}$ & Immediately, 0 days & $\begin{array}{l}\text { When able to jump pain } \\
\text { free }\end{array}$ & $\begin{array}{l}\text { When able to jump and } \\
\text { strengthen pain free }\end{array}$ & $\begin{array}{l}>4 \text { weeks after } \\
\text { return to run }\end{array}$ \\
\hline $\begin{array}{l}\text { Stress fracture } \\
\text { noncritical }\end{array}$ & 6-8 weeks & $\begin{array}{l}\text { Core: Immediately Leg: } \\
>3 \text { weeks }\end{array}$ & $\begin{array}{l}\text { When full weight bearing } \\
\text { (out of boot or off } \\
\text { crutches) }\end{array}$ & $\begin{array}{l}\sim 8 \text { weeks or when able } \\
\text { to hop one-legged and } \\
\text { be palpated without } \\
\text { pain at site }\end{array}$ & $\begin{array}{l}\sim 8 \text {-10 weeks once able to do } \\
\text { jump training, can introduce } \\
\text { running intervals }\end{array}$ & $\begin{array}{l}>4 \text { weeks after } \\
\text { return to run }\end{array}$ \\
\hline $\begin{array}{l}\text { Stress fracture } \\
\text { critical, high risk }\end{array}$ & $\begin{array}{l}\geq 12 \text { weeks (out to } 6 \\
\text { months) }\end{array}$ & $\begin{array}{l}\text { Core: Immediately out } \\
\text { to } 8 \text { weeks depending } \\
\text { on injury location } \\
\text { Leg: } 8-12 \text { weeks or } \\
\text { when able to bear full } \\
\text { weight }\end{array}$ & $\begin{array}{l}\text { Can begin with full weight } \\
\text { bearing }\end{array}$ & $\begin{array}{l}>12 \text { to } 24 \text { weeks when } \\
\text { able to do hopping } \\
\text { one-legged and be } \\
\text { palpated without pain } \\
\text { at site }\end{array}$ & $\begin{array}{l}\sim 12-20 \text { weeks once able to do } \\
\text { jump training, can introduce } \\
\text { running intervals }\end{array}$ & $\begin{array}{l}>5-6 \text { weeks after } \\
\text { return to run }\end{array}$ \\
\hline Acute & $\begin{array}{l}\text { 7-10 day out to } 8 \\
\text { weeks }\end{array}$ & $\begin{array}{l}\text { Core: Immediately Leg: } \\
\text { immediately, } \\
\text { activities are based on } \\
\text { pain tolerance }\end{array}$ & $\begin{array}{l}\text { Immediately, activities } \\
\text { based on pain tolerance }\end{array}$ & $\begin{array}{l}\text { As soon as stability and } \\
\text { proprioception are } \\
\text { demonstrated }\end{array}$ & $\begin{array}{l}\text { As soon as stability and } \\
\text { proprioception are } \\
\text { demonstrated }\end{array}$ & $\begin{array}{l}\text { When stability and } \\
\text { proprioception } \\
\text { are shown }\end{array}$ \\
\hline
\end{tabular}


heel raise, and plyometric one-leg side hop with three difficulty levels 4 times per week. ${ }^{83}$ These balance exercises and plyometrics, when performed per protocol, significantly reduce the number of substantial injuries by $8.5 \%$ compared to the control group (defined as any physical complaint resulting in moderate or severe reductions in training volume, moderate or severe reduction in performance, or complete inability to participate in sports). Low- or high-intensity plyometrics should also be used as part of the rehabilitation programs for runners with joint injury to the ankle (ankle sprain, chronic ankle instability) ${ }^{72}$ and knee (knee ligaments, anterior cruciate ligament strain). ${ }^{84,85}$

\section{When to Start Injury Prevention Before Competition}

Ideally, injury prevention exercise does not stop throughout the year irrespective of run training volume or season. At minimum, elite orienteers used a 6-8 week precompetition stage before competitive season to allow neuromuscular and skeletal adaptations to occur for short events. ${ }^{83}$ Longer trail events $>100 \mathrm{~K}$ will require more preparation, which may range from 6 months to 1 year depending on physical starting point, habitual training distance, and body weight. Prehabilitation should begin at the start of the training process for any event.

\section{Safe Training Participation}

Four additional methods to improve safety on the trail are presented here. First, during downhill sections of trail, elevations in joint loading and energy cost may be attenuated by maintaining the cadence within $\pm 5 \%$ of the cadence normally adopted in level running. ${ }^{86}$ Maintaining preferred cadence going downhill avoids increases in ground reaction force impulses and caloric cost, both of which could compromise performance over the event. ${ }^{86}$ Second, runners can acutely reduce their impact loading and patellofemoral joint force in various terrain stretches by combining elevated step rate and adopting a more forefoot strike. ${ }^{87,88}$ Third, during training and preparatory phases, trail runners should practice navigating sections of trails that are similar to the competition site. Evidence shows that trained runners learn to maintain dynamic stability through adjustment of leg stiffness and step and foot strike pattern when encountering obstacles in natural settings. ${ }^{89}$ Sessions of repeated running practice on challenging sections of trail may help the runner learn adaptive movement and step-to-step stabilization when faced with these conditions on the trail. Fourth, deliberate inclusion of brief rest intervals into the training runs can help runners prevent running through fatigue and refocus on the abdominal bracing and safe mechanics before restarting.

\section{Rehabilitation}

After injury, rehabilitation for the trail runner will involve 1) symptom management and reduction of loading, 2) recovery, 3) rebuilding, and 4) return to sport. ${ }^{20}$ Depending on the type and severity of the injury, the content of the stages of rehabilitation will vary (Table 1). For example, bony stress injuries (foot, tibia, femoral shaft, and pelvis) will involve relative or absolute unloading for 6-24 weeks, graduated reloading therapy protocols over a period of weeks and rebuilding of neuromuscular strength and balance from the trunk to the foot. The exercises described in the previous sections can be prescribed here and should be performed as soon as medically safe and continued during the rehabilitation process. In cases of high-risk stress fractures, where fracture progression, nonunion, and delayed healing are likely (femoral neck tension side, fifth metatarsal, anterior tibia, great to sesamoids, talus and tarsal navicular) nonweight bearing and/or immobilization and surgery may be required. ${ }^{90}$ In addition to physical therapy, rehabilitation may also involve sports nutrition, endocrinology, and psychology to help manage and treat the injury and runner, depending on overall clinical presentation. Initial reduction of loading should be followed by pain-free participation during and after normal activities and normal walking gait. Maintenance of cardiovascular conditioning during phases 2 and 3 is achieved through body weight-supported cycling, deep-water running, or antigravity treadmill training. The exercises described in the previous sections will be applied here as part of the phases 2-4 when the runner is cleared to rehabilitate. During phase 4 , there is a gradual reintroduction to 30 minutes of running with slow shift in running/walking ratios out to 4 months, when continual jogging is introduced. Slow progression from jogging to running can occur, provided the runner is pain-free. ${ }^{91}$

For chronic soft tissue injuries, like patellofemoral pain or ITB syndrome, symptoms may be managed with therapy, and training volume may be better maintained early in the rehabilitation program than with bony injuries. The time frame for rehabilitation of these soft tissue injuries is considerably shorter and is dependent on the pain tolerance of the runner. Symptom management that is initiated during stage 1 will continue during all stages of rehabilitation and involve education on pain monitoring. ${ }^{47}$ Consistent performance of the exercises described in the previous sections should transition from rehabilitation to part of the normal running routine.

\section{Conclusions}

The most common region for musculoskeletal injury in trail running is the lower leg; over $70 \%$ of musculoskeletal injuries are due to overuse, and ankle sprains are the most common acute injury. Safe trail running 
participation can be achieved through appropriate complete kinetic chain prehabilitation programs (comprising dynamic flexibility, neuromotor strength and balance, and plyometrics), practice on similar terrain with hills, understanding of musculoskeletal pain cues, and acutely adapting running technique to the route. Rehabilitation will involve similar exercise components, but it will incorporate rest and active rest on the basis of type of injury.

\section{References}

1. International Trail Running Association. Discover trail running, https://itra.run/About/DiscoverTrailRunning. Accessed August 11, 2021.

2. Orienteering USA. What is Orienteering?, https:// orienteeringusa.org/explore/what-is-orienteering/. Accessed August 11, 2021.

3. Viljoen CT, Sewry N, Schwellnus MP, Janse van Rensburg DC, Swanevelder S, Jordaan E. Independent risk factors predicting gradual onset injury in 2824 trail running race entrants: SAFER XVIII Study. Wilderness Environ Med 2021;32:293-301. doi:10.1016/j.wem.2021.04.002.

4. Viljoen CT, Janse van Rensburg DC, Verhagen E, et al. Epidemiology of injury and illness among trail runners: A systematic review. Sports Med 2021;51:917-943. doi:10. 1007/s40279-020-01418-1.

5. Viljoen CT, Janse van Rensburg DCC, Jansen van Rensburg A, et al. One in four trail running race entrants sustained an injury in the 12 months training preceding the 2019 SkyRun race. Phys Ther Sport 2021;47:120-126. doi:10.1016/j.ptsp.2020.11.029.

6. Gajardo-Burgos R, Monrroy-Uarac M, BarríaPailaquilén RM, et al. Frequency of injury and illness in the final 4 weeks before a trail running competition. Int $J$ Environ Res Public Health 2021;18:5431. doi:10.3390/ ijerph18105431.

7. Matos S, Silva B, Clemente FM, Pereira J. Runningrelated injuries in Portuguese trail runners: A retrospective cohort study. J Sports Med Phys Fitness 2021;61: 420-427. doi:10.23736/S0022-4707.20.11304-5.

8. Malliaropoulos N, Mertyri D, Tsaklis P. Prevalence of injury in ultra trail running. Human Movement 2015;16: 52-59. doi:10.1515/humo-2015-0026.

9. González-Lázaro J, Arribas-Cubero HF, RodríguezMarroyo JA. Muskuloskeletal injuries in mountain running races: A 5 seasons study. Injury 202 1;52:747-749. doi:10.1016/j.injury.2020.10.045.

10. Hoffman MD, Fogard K. Factors related to successful completion of a 161-km ultramarathon. Int J Sports Physiol Perform 2011;6:25-37. doi:10.1123/ijspp.6.1.25.

11. Scheer BV, Murray A Al. Andalus Ultra Trail: An observation of medical interventions during a $219-\mathrm{km}, 5$-day ultramarathon stage race. Clin J Sport Med 2011;21: 444-446. doi:10.1097/JSM.0b013e318225b0df.

12. Linko PE, Blomberg HK, Frilander HM. Orienteering competition injuries: injuries incurred in the Finnish Jukola and Venla relay competitions. Br J Sports Med 1997;31:205-208. doi:10.1136/bjsm.31.3.205.
13. von Rosen P, Heijne AI-LM, Frohm A. Injuries and associated risk factors among adolescent elite orienteerers: A 26-week prospective registration study. J Athl Train 2016;51:321-328. doi:10.4085/1062-6050-51.5.01.

14. Roos L, Taube W, Zuest P, Clénin G, Wyss T. Musculoskeletal injuries and training patterns in junior elite orienteering athletes. Biomed Res Int 2015;2015:259531. doi:10.1155/2015/259531.

15. Linde F. Injuries in orienteering. Brit J Sports Med 1986;20: 125-127. doi:10.1136/bjsm.20.3.125.

16. Larsen P, Elsoe R, Graven-Nielsen T, Laessoe U, Rasmussen S. Decreased muscle strength is associated with impaired long-term functional outcome after intramedullary nailing of femoral shaft fracture. Eur J Trauma Emerg Surg 2015;41:673-681. doi:10.1007/s00068-0140488-2.

17. Moraes R. A model for selecting alternate foot placement during human locomtion. Psychol Neurosci 2014;7: 319-329.

18. Patla AE. Understanding the roles of vision in the control of human locomotion. Gait Posture 1997;5:54-69. doi:10. 1016/S0966-6362(96)01109-5.

19. Garcia MC, Gust G, Bazett-Jones DM. Tibial acceleration and shock attenuation while running over different surfaces in a trail environment. J Sci Med Sport 2021;24: 1161-1165. doi:10.1016/j.jsams.2021.03.006.

20. Silbernagel KG, Hanlon S, Sprague A. Current clinical concepts: Conservative management of Achilles tendinopathy. J Athl Train 2020;55:438-447. doi:10.4085/10626050-356-19.

21. Aderem J, Louw QA. Biomechanical risk factors associated with iliotibial band syndrome in runners: A systematic review. BMC Musculoskelet Disord 2015;16:356. doi:10. 1186/s12891-015-0808-7.

22. Chu JJ, Caldwell GE. Stiffness and damping response assoiated with shock attenuation in downhill running. J Appl Physiol 2004;20:291-308.

23. Giandolini M, Pavailler S, Samozino P, Morin J-B, Horva N. Foot strike pattern and impact continuous measurements during a trail running race: proof of concept in a world-class athlete. Footwear Sci 2015;7: 127-137.

24. Mizrahi J, Verbitsky O, Isakov E. Shock accelerations and attenuation in downhill and level running. Clin Biomech 2000;15:15-20. doi:10.1016/S0268-0033(99)00033-9.

25. Turner $\mathrm{CH}$, Wang T, Burr DB. Shear strength and fatigue properties of human cortical bone determined from pure shear tests. Calcif Tissue Int 2001;69:373-378. doi:10.1007/ s00223-001-1006-1.

26. Hajiloo B, Anbarian M, Esmaeili H, Mirzapour M. The effects of fatigue on synergy of selected lower limb muscles during running. J Biomech 2020;103:109692. doi:10. 1016/j.jbiomech.2020.109692.

27. Hamzavi B, Esmaeili H. Effects of running-induced fatigue on plantar pressure distribution in runners with different strike types. Gait Posture 2021;88:132-137. doi:10.1016/j. gaitpost.2021.05.018.

28. Gerlach KE, White SC, Burton HW, Dorn JM, Leddy JJ, Horvath PJ. Kinetic changes with fatigue and relationship 
to injury in female runners. Med Sci Sports Exerc 2005;37: 657-663. doi:10.1249/01.mss.0000158994.29358.71.

29. Encarnación-Martínez A, Sanchis-Sanchis R, PérezSoriano P, García-Gallart A. Relationship between muscular extensibility, strength and stability and the transmission of impacts during fatigued running. Sports Biomech Published online August 2020;24:1-17. doi:10. 1080/14763141.2020.1797863.

30. Sado N, Yoshioka S, Fukashiro S. A biomechanical study of the relationship between running velocity and threedimensional lumbosacral kinetics. J Biomech 2019;94: 158-164. doi:10.1016/j.jbiomech.2019.07.038.

31. Hart JM, Kerrigan DC, Fritz JM, Ingersoll CD. Jogging kinematics after lumbar paraspinal muscle fatigue. $J$ Athl Train 2009;44:475-481. doi:10.4085/1062-6050-44.5.475.

32. Mucha MD, Caldwell W, Schlueter EL, Walters C, Hassen A. Hip abductor strength and lower extremity running related injury in distance runners: A systematic review. J Sci Med Sport 2017;20:349-355. doi:10.1016/j. jsams.2016.09.002.

33. Souza RB, Powers CM. Differences in hip kinematics, muscle strength, and muscle activation between subjects with and without patellofemoral pain. J Orthop Sports Phys Ther 2009;39:12-19. doi:10.2519/jospt.2009.2885.

34. Bramah C, Preece SJ, Gill N, Herrington L. Is there a pathological gait associated with common soft tissue running injuries? Am J Sports Med 2018;46:3023-3031. doi:10.1177/0363546518793657.

35. Bramah C, Preece SJ, Gill N, Herrington L. Kinematic characteristics of male runners with a history of recurrent calf muscle strain injury. Int J Sports Phys Ther 2021;16: 732-740. doi:10.26603/001c.22971.

36. Sado N, Yoshioka S, Fukashiro S. The sidestep cutting manoeuvre requires exertion of lumbosacral lateral flexion torque to avoid excessive pelvic obliquity. Sports Biomech 2019;18:135-145. doi:10.1080/14763141.2019. 1572780 .

37. Willems TM, De Clercq D, Delbaere K, Vanderstraeten G, De Cock A, Witvrouw E. A prospective study of gait related risk factors for exercise-related lower leg pain. Gait Posture 2006;23:91-98. doi:10.1016/j.gaitpost.2004.12.004.

38. Hewett TE, Myer GD, Ford KR, et al. Biomechanical measures of neuromuscular control and valgus loading of the knee predict anterior cruciate ligament injury risk in female athletes: A prospective study. Am J Sports Med 2005;33:492-501. doi:10.1177/0363546504269591.

39. Myer GD, Ford KR, McLean SG, Hewett TE. The effects of plyometric versus dynamic stabilization and balance training on lower extremity biomechanics. Am J Sports Med 2006;34:445-455. doi:10.1177/0363546505281241.

40. Olsen O-E, Myklebust G, Engebretsen L, Bahr R. Injury mechanisms for anterior cruciate ligament injuries in team handball: A systematic video analysis. Am J Sports Med 2004;32:1002-1012. doi:10.1177/0363546503261724.

41. Messier SP, Martin DF, Mihalko SL, et al. A 2-year prospective cohort study of overuse running injuries: The Runners and Injury Longitudinal Study (TRAILS). Am J Sports Med 2018;46:2211-2221. doi:10.1177/0363546518773755.

42. Wang L-I. Lower extremity stiffness modulation: Effect of impact load of a landing task from different drop heights. Int J Sports Med 2009;10:186-193.
43. Lorimer AV, Hume PA. Stiffness as a risk factor for Achilles tendon injury in running athletes. Sports Med 2016;46:1921-1938. doi:10.1007/s40279-016-0526-9.

44. Pruyn EC, Watsford ML, Murphy AJ, et al. Relationship between leg stiffness and lower body injuries in professional Australian football. J Sports Sci 2012;30:71-78. doi: 10.1080/02640414.2011.624540.

45. Vincent HK, Kilgore JE, Chen C, Bruner M, Horodyski M, Vincent KR. Impact of body mass index on biomechanics of recreational runners. PM R 2020;12:1106-1112. doi:10. 1002 /pmrj. 12335.

46. Haghighat F, Ebrahimi S, Rezaie M, et al. Trunk, pelvis, and knee kinematics during running in females with and without patellofemoral pain. Gait Posture 2021;89:80-85. doi:10.1016/j.gaitpost.2021.06.023.

47. Vincent HK, Vincent KR. When is it safe to run? Applying four pain rules to running participation. Curr Sports Med Rep 2017;16:122. doi:10.1249/JSR.0000000000000362.

48. Vincent HK, Herman DC, Lear-Barnes L, et al. Setting standards for medically-based running analysis. Curr Sports Med Rep 2014;13:275-283. doi:10.1249/JSR. 0000000000000071.

49. Fyock M, Cortes N, Hulse A, Martin J. Gait retraining with real-time visual feedback to treat patellofemoral pain in adult recreational runners: A critically appraised topic. J Sport Rehabil 2020;29:675-679. doi:10.1123/jsr.20190094.

50. Barton CJ, Bonanno DR, Carr J, et al. Running retraining to treat lower limb injuries: a mixed-methods study of current evidence synthesised with expert opinion. $\mathrm{Br} \mathrm{J}$ Sports Med 2016;50:513-526. doi:10.1136/bjsports-2015095278.

51. McCrory JL, Martin DF, Lowery RB, et al. Etiologic factors associated with Achilles tendinitis in runners. Med Sci Sports Exerc 1999;31:1374-1381. doi:10.1097/00005768199910000-00003.

52. Messier SP, Edwards DG, Martin DF, et al. Etiology of iliotibial band friction syndrome in distance runners. Med Sci Sports Exerc 1995;27:951-960. doi:10.1249/00005768199507000-00002.

53. Messier SP, Davis SE, Curl WW, Lowery RB, Pack RJ. Etiologic factors associated with patellofemoral pain in runners. Med Sci Sports Exerc 1991;23:1008-1015.

54. Messier SP, Legault C, Schoenlank CR, Newman JJ, Martin DF, DeVita P. Risk factors and mechanisms of knee injury in runners. Med Sci Sports Exerc 2008;40:1873-1879. doi:10.1249/MSS.0b013e31817ed272.

55. Hreljac A, Marshall RN, Hume PA. Evaluation of lower extremity overuse injury potential in runners. Med Sci Sports Exerc 2000;32:1635-1641. doi:10.1097/00005768200009000-00018.

56. Mehl J, Diermeier T, Herbst E, et al. Evidence-based concepts for prevention of knee and ACL injuries. 2017 guidelines of the ligament committee of the German Knee Society (DKG). Arch Orthop Trauma Surg 2018;138:51-61. doi:10.1007/s00402-017-2809-5.

57. Dillon S, Burke A, Whyte EF, O'Connor S, Gore S, Moran KA. Do injury-resistant runners have distinct differences in clinical measures compared to recently injured runners? Med Sci Sports Exerc 2021;53:1807-1817. doi:10. 1249/MSS.0000000000002649. 
58. Baggaley M, Willy RW, Meardon SA. Primary and secondary effects of real-time feedback to reduce vertical loading rate during running. Scand J Med Sci Sports 2017;27:501-507. doi:10.1111/sms.12670.

59. Brindle RA, Ebaugh DD, Willson JD, Finley MA, Shewokis PA, Milner CE. Relationships of hip abductor strength, neuromuscular control, and hip width to femoral length ratio with peak hip adduction angle in healthy female runners. J Sports Sci 2020;38:2291-2297. doi:10.1080/02640414.2020.1779489.

60. Foch E, Brindle RA, Milner CE. Weak associations between hip adduction angle and hip abductor muscle activity during running. J Biomech 2020;1 10:109965. doi:10. 1016/j.jbiomech.2020.109965.

61. Moffit TJ, Montgomery MM, Lockie RG, Pamukoff DN. Association between knee- and hip-extensor strength and running-related injury biomechanics in collegiate distance runners. J Athl Train 2020;55:1262-1269. doi:10.4085/ 1062-6050-0532.19.

62. Dejong AF, Koldenhoven RM, Hertel J. Proximal adaptations in chronic ankle instability: Systematic review and meta-analysis. Med Sci Sports Exerc 2020;52:1563-1575. doi:10.1249/MSS.0000000000002282.

63. Benjaminse A, Welling W, Otten B, Gokeler A. Novel methods of instruction in ACL injury prevention programs. A systematic review. Phys Ther Sport 2015;16: 176-186. doi:10.1016/j.ptsp.2014.06.003.

64. Matias AB, Taddei UT, Duarte M, Sacco ICN. Protocol for evaluating the effects of a therapeutic foot exercise program on injury incidence, foot functionality and biomechanics in long-distance runners: a randomized controlled trial. BMC Musculoskel Disord 2016;17:160.

65. McKeon PO, Hertel J, Bramble D, Davis I. The foot core system: A new paradigm for understanding intrinsic foot muscle function. Br J Sports Med 2015;49:290. doi:10. 1136/bjsports-2013-092690.

66. Taddei UT, Matias AB, Ribeiro FIA, Bus SA, Sacco ICN. Effects of a foot strengthening program on foot muscle morphology and running mechanics: A proof-of-concept, single-blind randomized controlled trial. Phys Ther Sport 2020;42:107-115. doi:10.1016/j.ptsp.2020.01.007.

67. Jung D-Y, Koh E-K, Kwon O-Y. Effect of foot orthoses and short-foot exercise on the cross-sectional area of the abductor hallucis muscle in subjects with pes planus: a randomized controlled trial. J Back Musculoskelet Rehabil 201 1;24:225-231. doi:10.3233/BMR-2011-0299.

68. Kısacık P, Tunay VB, Bek N, Atay ÖA, Selfe J, Karaduman AA. Short foot exercises have additional effects on knee pain, foot biomechanics, and lower extremity muscle strength in patients with patellofemoral pain. J Back Musculoskelet Rehabil 202 1;34:1093-1104. doi: 10.3233/BMR-200255.

69. Sulowska I, Mika A, Oleksy Ł, Stolarczyk A. The influence of plantar short foot muscle exercises on the lower extremity muscle strength and power in proximal segments of the kinematic chain in long-distance runners. Biomed Res Int 2019;2019:6947273. doi:10.1155/2019/6947273.

70. Fredericson M, Moore T. Muscular balance, core stability, and injury prevention for middle- and long-distance runners. Phys Med Rehabil Clin N Am 2005;16:669-689. doi:10.1016/j.pmr.2005.03.001.
71. Schuermans J, Danneels L, Van Tiggelen D, Palmans T, Witvrouw E. Proximal neuromuscular control protects against hamstring injuries in male soccer players: A prospective study with electromyography time-series analysis during maximal sprinting. Am J Sports Med 2017;45: 1315-1325. doi:10.1177/0363546516687750.

72. Huang P-Y, Jankaew A, Lin C-F. Effects of plyometric and balance training on neuromuscular control of recreational athletes with functional ankle instability: A randomized controlled laboratory study. Int J Environ Res Public Health 2021;18:5269. doi:10.3390/ijerph18105269.

73. Emery CA, Rose MS, McAllister JR, Meeuwisse WH. A prevention strategy to reduce the incidence of injury in high school basketball: A cluster randomized controlled trial. Clin J Sport Med 2007;17:17-24. doi:10.1097/JSM. 0b013e31802e9c05.

74. Silva PB, Oliveira AS, Mrachacz-Kersting N, Kersting UG. Effects of wobble board training on single-leg landing neuromechanics. Scand J Med Sci Sports 2018;28:972-982. doi:10.1111/sms.13027.

75. Trowell D, Vicenzino B, Saunders N, Fox A, Bonacci J. Effect of strength training on biomechanical and neuromuscular variables in distance runners: A systematic review and meta-analysis. Sports Med 2020;50:133-150. doi: 10.1007/s40279-019-01184-9.

76. Vatovec R, Kozinc Ž, Šarabon N. Exercise interventions to prevent hamstring injuries in athletes: A systematic review and meta-analysis. Eur J Sport Sci 2020;20:992-1004. doi:10.1080/17461391.2019.1689300.

77. van Dyk N, Behan FP, Whiteley R. Including the Nordic hamstring exercise in injury prevention programmes halves the rate of hamstring injuries: A systematic review and meta-analysis of 8459 athletes. Br J Sports Med 2019;53:1362-1370. doi:10.1136/bjsports-2018-100045.

78. Hrysomallis C. Relationship between balance ability, training and sports injury risk. Sports Med 2007;37: 547-556. doi:10.2165/00007256-200737060-00007.

79. Mendez-Rebolledo G, Figueroa-Ureta R, Moya-Mura F, Guzmán-Muñoz E, Ramirez-Campillo R, Lloyd RS. The protective effect of neuromuscular training on the medial tibial stress syndrome in youth female track-and-field athletes: A clinical trial and cohort study. J Sport Rehabil In press. doi:10.1123/jsr.2020-0376.

80. Sandrey MA, Mitzel JG. Improvement in dynamic balance and core endurance after a 6-week core-stability-training program in high school track and field athletes. J Sport Rehabil 2013;22:264-271. doi:10.1123/jsr.22.4.264.

81. Sugimoto D, Myer GD, Foss KDB, Hewett TE. Specific exercise effects of preventive neuromuscular training intervention on anterior cruciate ligament injury risk reduction in young females: meta-analysis and subgroup analysis. Br J Sports Med 2015;49:282-289. doi:10.1136/ bjsports-2014-093461.

82. Markovic G, Mikulic P. Neuro-musculoskeletal and performance adaptations to lower-extremity plyometric training. Sports Med 2010;40:859-895. doi:10.2165/ 11318370-000000000-00000.

83. Halvarsson B, von Rosen P. Could a specific exercise programme prevent injury in elite orienteerers? A randomised controlled trial. Phys Ther Sport 2019;40:177-183. doi:10.1016/j.ptsp.2019.09.010. 
84. Clarsen B, Myklebust G, Bahr R. Development and validation of a new method for the registration of overuse injuries in sports injury epidemiology: The Oslo Sports Trauma Research Centre (OSTRC) Overuse Injury Questionnaire. Br J Sports Med 2013;47:495-502. doi:10.1136/ bjsports-2012-091524.

85. Chmielewski TL, George SZ, Tillman SM, et al. Low- versus high-intensity plyometric exercise during rehabilitation after anterior cruciate ligament reconstruction. Am J Sports Med 2016;44:609-617. doi:10.1177/0363546515620583.

86. Vincent HK, Massengill C, Harris A, et al. Cadence impact on cardiopulmonary, metabolic and biomechanical loading during downhill running. Gait Posture 2019;71: 186-191. doi:10.1016/j.gaitpost.2019.04.022.

87. Huang Y, Xia H, Chen G, Cheng S, Cheung RTH, Shull PB. Foot strike pattern, step rate, and trunk posture combined gait modifications to reduce impact loading during running. J Biomech 2019;86:102-109. doi:10.1016/j.jbiomech.2019.01.058.

88. Dos Santos AF, Nakagawa TH, Serrão FV, Ferber R. Patellofemoral joint stress measured across three different running techniques. Gait Posture 2019;68:37-43. doi:10. 1016/j.gaitpost.2018.11.002.

89. Larsen RJ, Jackson WH, Schmitt D. Mechanisms for regulating step length while running towards and over an obstacle. Hum Mov Sci 2016;49:186-195. doi:10.1016/j. humov.2016.07.002.

90. McInnis KC, Ramey LN. High-risk stress fractures: diagnosis and management. PM R 2016;8:S113-S124. doi:10. 1016/j.pmrj.2015.09.019 (3 Suppl).

91. Warden SJ, Davis IS, Fredericson M. Management and prevention of bone stress injuries in long-distance runners. J Orthop Sports Phys Ther 2014;44:749-765. doi:10. 2519 /jospt.2014.5334. 